EPJ Web of Conferences 59, 02004 (2013)

DOI: $10.1051 /$ epjconf/20135902004

(C) Owned by the authors, published by EDP Sciences, 2013

\title{
Shock timing on the National Ignition Facility: First experiments
}

P.M. Celliers ${ }^{1, a}$, H.F. Robey ${ }^{1}$, T.R. Boehly ${ }^{2}$, E. Alger ${ }^{3}$, S. Azevedo ${ }^{1}$, L.V. Berzins ${ }^{1}$, S.D. Bhandarkar ${ }^{1}$, M.W. Bowers ${ }^{1}$, S.J. Brereton ${ }^{1}$, D. Callahan ${ }^{1}$, C. Castro ${ }^{1}$, H. Chandrasekaran ${ }^{1}$, C. Choate $^{1}$, D.S. Clark ${ }^{1}$, K.R. Coffee ${ }^{1}$, P.S. Datte ${ }^{1}$, E.L. Dewald ${ }^{1}$, P. DiNicola ${ }^{1}$, S. Dixit ${ }^{1}$, T. Döppner ${ }^{1}$, E. Dzenitis ${ }^{1}$, M.J. Edwards ${ }^{1}$, J.H. Eggert ${ }^{1}$, J. Fair ${ }^{1}$, D.R. Farley ${ }^{1}$, G. Frieders ${ }^{1}$, C.R. Gibson ${ }^{3}$, E. Giraldez ${ }^{3}$, S. Haan ${ }^{1}$, B. Haid ${ }^{1}$, A.V. Hamza ${ }^{1}$, C. Haynam¹ ${ }^{1}$ D.G. Hicks ${ }^{1}$, D.M. Holunga ${ }^{1}$, J.B. Horner ${ }^{1}$, K. Jancaitis ${ }^{1}$, O.S. Jones ${ }^{1}$, D. Kalantar ${ }^{1}$, J.L. Kline ${ }^{4}$, K.G. Krauter ${ }^{1}$, J.J. Kroll ${ }^{1}$, K.N. LaFortune ${ }^{1}$, S. Le Pape ${ }^{1}$, T. Malsbury ${ }^{1}$, E.R. Mapoles ${ }^{1}$, N.B. Meezan ${ }^{1}$, J.L. Milovich ${ }^{1}$, J.D. Moody ${ }^{1}$, K. Moreno ${ }^{3}$, D.H. Munro ${ }^{1}$, A. Nikroo ${ }^{3}$, R.E. Olson ${ }^{5}$, T. Parham ${ }^{1}$, S. Pollaine ${ }^{1}$, H.B. Radousky ${ }^{1}$, G.F. Ross ${ }^{1}$, J. Sater ${ }^{1}$, M.B. Schneider ${ }^{1}$, M. Shaw ${ }^{1}$, R.F. Smith ${ }^{1}$, P.A. Sterne ${ }^{1}$, C.A. Thomas ${ }^{1}$, A. Throop ${ }^{1}$, R.P.J. Town ${ }^{1}$, D. Trummer ${ }^{1}$, B.M. Van Wonterghem ${ }^{1}$, C.F. Walters ${ }^{1}$, K. Widmann ${ }^{1}$, C. Widmayer ${ }^{1}$, B.K. Young ${ }^{1}$, L.J. Atherton ${ }^{1}$, G.W. Collins ${ }^{1}$, O.L. Landen ${ }^{1}$, J.D. Lindl ${ }^{1}$, B.J. MacGowan ${ }^{1}$, D.D. Meyerhofer ${ }^{2}$ and E.I. Moses ${ }^{1}$

1 Lawrence Livermore National Laboratory, Livermore, CA 94550, USA

2 Laboratory for Laser Energetics, University of Rochester, Rochester, NY 14423, USA

3 General Atomics, PO Box 85608, San Diego, CA 92186, USA

4 Los Alamos National Laboratory, Los Alamos, NM 87545, USA

5 Sanda National Laboratories, Albuquerque, NM 87185, USA

\begin{abstract}
An experimental campaign to tune the initial shock compression sequence of capsule implosions on the National Ignition Facility (NIF) was initiated in late 2010. The experiments use a NIF ignitionscale hohlraum and capsule that employs a re-entrant cone to provide optical access to the shocks as they propagate in the liquid deuterium-filled capsule interior. The strength and timing of the shock sequence is diagnosed with velocity interferometry that provides target performance data used to set the pulse shape for ignition capsule implosions that follow. From the start, these measurements yielded significant new information on target performance, leading to improvements in the target design. We describe the results and interpretation of the initial tuning experiments.
\end{abstract}

\section{INTRODUCTION}

The fuel layer in capsules imploded by indirect drive on the National Ignition Facility (NIF) is initially compressed by a series of four shock waves of increasing strength launched in a precise sequence through the capsule shell and the fuel. The shock waves are generated by a laser power profile composed

\footnotetext{
ae-mail: celliers1@llnl.gov
}

This is an Open Access article distributed under the terms of the Creative Commons Attribution License 2.0, which permits unrestricted use, distribution, and reproduction in any medium, provided the original work is properly cited. 

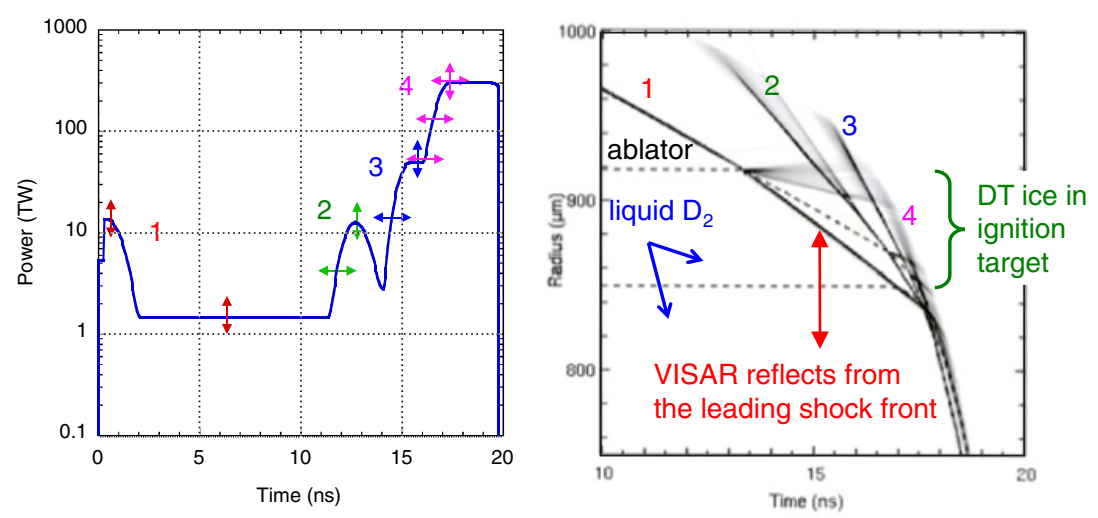

Figure 1. Laser power history on the left; each segment of the pulse identified by the annotations launches a shock which propagates into the target as shown on the lagrangian radius versus time plot on the right.

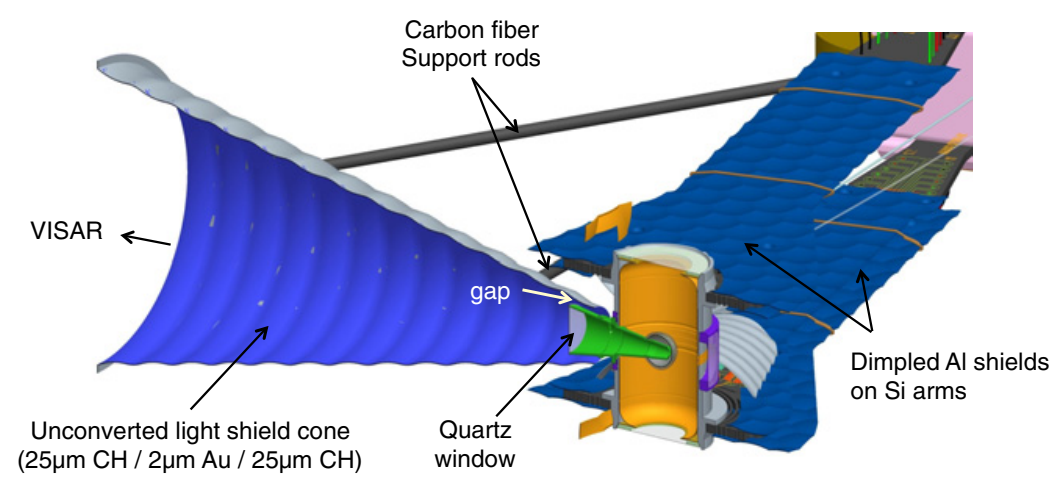

Figure 2. Cut-away drawing of the target. The capsule and interior cone is filled with liquid deuterium.

of a series of pulses, Fig. 1(a), each of which launches a shock that travels through the target faster than the preceding shocks, eventually to overtake and merge with them. The fuel entropy depends critically on the details of the shock merger events. In the ideal case each element of the fuel layer must be compressed by each shock in succession, a condition that will maintain low entropy in the fuel layer. This situation is achieved by controlling the strength and launch times of these shocks such that all four shocks merge nearly simultaneously at a common point near the fuel ice-gas interface, Fig. 1(b). This situation of near simultaneous mergers is achieved by making adjustments to the power history of the drive pulse, which in turn adjusts the strength and timing of the shocks. Over the previous decade we have developed an experimental plan to diagnose the shock sequence in order to set the pulse shape [1-3]. This plan has now been realized with the first experiments performed in late 2010. We describe the initial results obtained on NIF using this technique.

\section{TARGET DESIGN AND VELOCITY MEASUREMENT}

The shock waves are probed optically with a Doppler-shift diagnostic known as the Velocity Interferometer System for Any Reflector (VISAR) [4-6]. The measurements are performed from the inside surface of a standard implosion capsule contained within the same ignition hohlraum as is used for the implosion experiments, thus in the same spherical geometry to provide a close approximation 

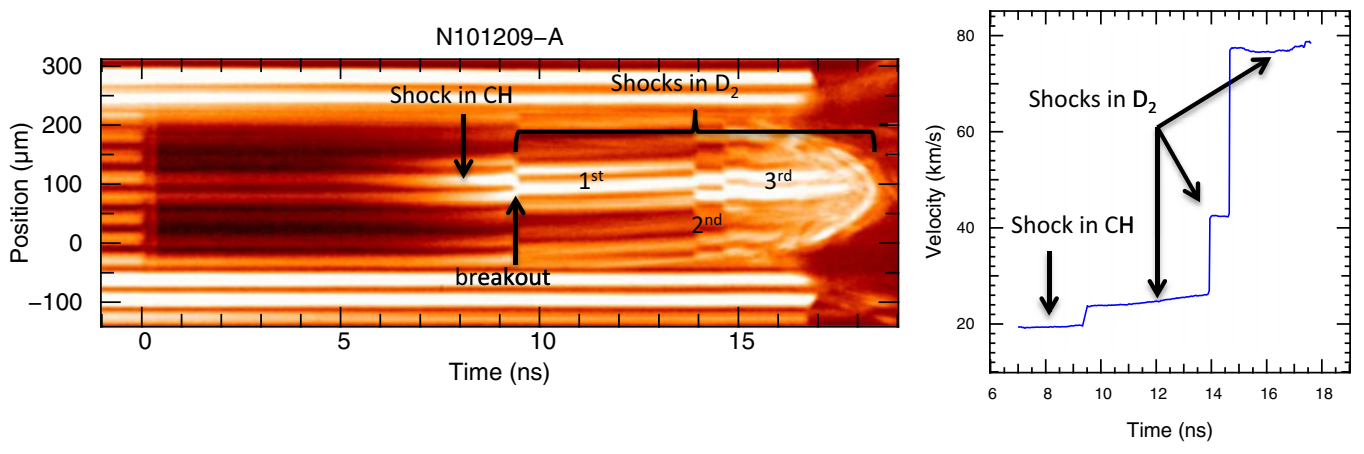

Figure 3. Sample streak record with corresponding velocity profile. Breakout and merger events are identified.

to the implosion conditions. A gold cone inserted into the target through the hohlraum wall and into the capsule provides optical access to the ablator surface. Instead of a deuterium-tritium (DT) ice layer, the interior volume of the capsule and gold cone is completely filled with liquid deuterium $\left(D_{2}\right)$ and sealed by a transparent alpha-quartz window situated $\sim 6 \mathrm{~mm}$ from the hohlraum axis. External to the hohlraum is an additional shielding cone designed to protect the line-of-sight from plasma filling and $\mathrm{x}$-ray preheating due to the unconverted light that irradiates the volume surrounding the target out to a radius of $40 \mathrm{~mm}$. This cone is nested around the internal cone but thermally isolated from the target by a vacuum gap.

The $\mathrm{CH}$ ablator and liquid deuterium are optically transparent wide bandgap insulators. Under shock compression to pressures above $\sim 20 \mathrm{GPa}$ in $\mathrm{D}_{2}$ and $\sim 100 \mathrm{GPa}$ in $\mathrm{CH}$ these materials become ionized and the shock front behaves like an optically reflecting metallic mirror [7,8]. The probe beam is reflected directly from the leading shock front, and imaged onto a streak camera after passing through the VISAR interferometer. The fringe phases observed on the streak record are directly proportional to the shock velocity. The VISAR provides information relating only to the leading shock front, since the material behind the leading shock front is optically opaque. Information about the propagation of the shocks behind the leading shock must be inferred from the timing of the overtake events, and the subsequent shock velocities. To observe each of the shocks in sequence we start with a pulse that is stretched out in time by 1-2 ns. An example of a data record in Fig. 3 shows the raw VISAR streak record and corresponding velocity profile for a 3-shock sequence. Detailed examination of the data sets show that the NIF VISAR diagnostic fully meets the requirements for timing the shocks (velocity resolution $<0.35 \mathrm{~km} / \mathrm{s}$ and absolute timing accuracy $<50 \mathrm{ps}$ ).

\section{INITIAL RESULTS}

The first two shots revealed a significant discrepancy between the observed shock velocity history and pre-shot predictions based on simulations. The shock arrival at the $\mathrm{CH}-\mathrm{D}_{2}$ interface was found to be several ns late, and its velocity too high, close to the second shock level. The leading hypothesis to explain this result was that residual chamber gases $\left(\mathrm{N}_{2}, \mathrm{O}_{2}, \mathrm{H}_{2} \mathrm{O}\right.$ etc, $)$ had condensed on the laser entrance hole (LEH) windows to form ice layers of the order of 1-2 $\mu \mathrm{m}$ thick. The presence of the ice layer impeded the initial heating of the hohlraum such that the first shock was weak and travelled so slowly that the second shock merged with it in the $\mathrm{CH}$ ablator prior to its emergence into the liquid $\mathrm{D}_{2}$. This hypothesis was confirmed by two more shots for which the power of the picket and trough on the laser pulse was increased by a factor of two in order to burn through the ice layer at the beginning of the pulse. This pair of shots resulted in velocity histories that were reproducible and in agreement with predictions (which accounted for the ice). On the second of this pair the pulses 2 and 3 were shifted earlier in time, and the observed overtake events shifted in agreement with expectations. 


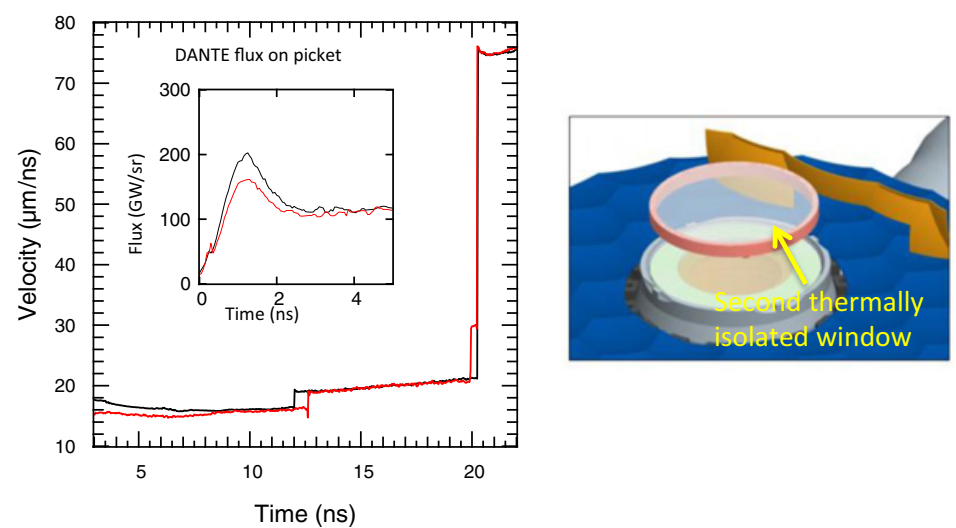

Figure 4. Velocity profiles for targets incorporating LEH "storm windows" showing a high degree of reproducibility for two successive shots. A small reduction in the picket power of the second pulse as shown by the DANTE flux (see inset) produced a slightly later $\mathrm{CH}-\mathrm{D}_{2}$ breakout and a slightly earlier second shock merge time, in agreement with post-shot analysis.

A target modification to mitigate the LEH-ice problem was implemented: it consisted of a thermally isolated membrane (called a "storm window") placed $500 \mu \mathrm{m}$ away from the LEH window to provide a barrier preventing the chamber gases from condensing on the cold LEH-window. The membrane was heated slightly by ambient IR radiation such that its temperature remained above the ice condensation temperature. A subsequent series of two shots using this modification demonstrated high quality data in good agreement with pre-shot simulations. With the successful mitigation of the LEH-ice problem the platform was ready for embarking on the first detailed series of tuning shots.

\section{CONCLUSION}

The initial experiments demonstrating the shock timing technique on NIF completed in January 2011 were followed by detailed tuning campaigns in May and August 2011. From these campaigns it was demonstrated that adequate shock timing for a given target configuration could be achieved with less than five shots [9]. After the first detailed tuning series in May subsequent implosion shots using the tuned pulse achieved a factor of two increase in the fuel areal density relative to previous implosions with untuned pulses as inferred from the neutron down-scatter fraction. This result provided an unambiguous confirmation that the pulse shape determined from the shock timing tuning experiments produces lower fuel entropy during the implosions.

\section{References}

[1] D. H. Munro, P. M. Celliers, G. W. Collins et al., Phys. Plasmas, 8, 2245 (2001)

[2] T. R. Boehly, D. Munro, P. M. Celliers et al., Phys. Plasmas, 16, 056302 (2009)

[3] O. L. Landen, T. R. Boehly, D. K. Bradley et al., Phys. Plasmas, 17, 056301 (2011)

[4] L. M. Barker and R. E. Hollenbach, J. Appl. Phys., 43, 4669 (1972)

[5] P. M. Celliers, D. K. Bradley, G. W. Collins et al., Rev. Sci. Instrum., 75, 4916 (2004)

[6] R. M. Malone, G. A. Capelle, J. R. Celeste et al., Proc. SPIE-OSA 6342634220 (2006)

[7] P. M. Celliers, G. W. Collins, L. B. DaSilva et al., Phys. Rev. Lett., 84, 5564 (2000)

[8] M. A. Barrios, D. G. Hicks, T. R. Boehly et al., Phys. Plasmas, 17, 056301 (2010)

[9] H. F. Robey et al., these proceedings. 